\title{
DESENVOLVIMENTO DA LARVA-ALFINETE EM TURFA E VERMICULITA
}

\author{
LETICIA HELLWIG ${ }^{1}$, JEFFERSON SILVEIRA TEODORO ${ }^{1}$, CALISC DE OLIVEIRA TRECHA ${ }^{1}$, \\ CAROLINI VAZ DE LIMA ${ }^{1}$, LAUREN BITTENCOURT MEDINA ${ }^{1}$ \\ e ANA PAULA SCHNEID AFONSO DA ROSA ${ }^{2}$
}

${ }^{1}$ UFPel, Capão do Leão,RS, Brasil,leticia_hellwig@hotmail.com,jeffagroufla@gmail.com, calisc_oliveiratrecha@yahoo.com.br, karolimavaz@yahoo.com,laurenmedina@live.com;

${ }^{2}$ Embrapa Clima Temperado, Pelotas, RS.ana.afonso@embrapa.br

Revista Brasileira de Milho e Sorgo, v.14, n.1, p. 1-9, 2015

RESUMO - A Diabrotica speciosa (Germar) (Coleoptera: Chrysomelidae) é uma importante praga para diversas culturas. O objetivo deste trabalho foi aperfeiçoar o método de criação da larva-alfinete em condições de laboratório. Foram comparados quatro sistemas para criação das larvas, sendo dois deles com transferência e dois sem transferência de larvas, constituídas de plântulas de milho mantidas em turfa e vermiculita. Os seguintes parâmetros biológicos foram avaliados: duração e viabilidade no período larva-adulto; períodos de pré-oviposição e de oviposição; longevidade de machos e de fêmeas; fecundidade e viabilidade; taxa líquida de reprodução (Ro); duração média em semanas de uma geração (T); capacidade inata de aumentar em número (rm); e razão finita de aumento $(\lambda)$ de adultos de $D$. speciosa. A partir dos resultados obtidos, pode-se constatar que não houve influência dos substratos e das técnicas de criação empregadas sobre os períodos de pré-oviposição e oviposição, longevidade de machos e fêmeas e também na fecundidade total. No entanto, houve influência para a viabilidade larval, em que se obteve uma viabilidade maior no tratamento sem transferência e com transferência quando usado como substrato turfa e vermiculita, respectivamente; uma maior duração do período larva-adulto quando os insetos foram criados em substrato vermiculita, independente da transferência; e na viabilidade dos ovos, que foi maior no tratamento sem transferência para os dois substratos. Os resultados da tabela de fertilidade indicaram que o potencial de reprodução de $D$. speciosa aumenta, significativamente, quando larvas são criadas em turfa sem transferência e vermiculita com transferência.

Palavras-chave: métodos de criação; laboratório; viabilidade larva-adulto; Diabrotica speciosa.

\section{DEVELOPMENT OF THE CORN ROOTWORM IN PEAT AND VERMICULITE}

ABSTRACT - The Diabrotica speciosa (Germar) (Coleoptera: Chrysomelidae) is an important pest for several crops. The purpose of this work was to improve the method of rearing corn rootworm in lab conditions. Four systems were compared for rearing larvae, two with transference and two without transferring the larvae, constituted by maize seedling kept in peat and vermiculite. The following biological parameters were assessed: duration and feasibility in the adult-larva period, pre-oviposition and oviposition periods, males and females longevity, fertility and feasibility, net reproduction rate (Ro), average duration of a generation in weeks (T), innate capacity to increase in number (rm) and increase finite rate $(\lambda)$ of $D$. speciosa adults. Based on the results obtained, it could be noticed that there was no influence of the substrates and rearing techniques used in the pre-oviposition and oviposition periods, males and females longevity and also in the whole fertility. However, there was effect on larval feasibility, where a higher feasibility was obtained in the treatment without transferring and with transference when peat and vermiculite were used as substrates, respectively; a bigger duration of the adult-larva period when the insects were reared in vermiculite substrate, regardless the transference; and in the feasibility of the eggs, which was higher in the treatment without transference for the two substrates. The results of the fertility table indicated that the reproduction potential of the $D$. speciosa significantly increases when the larvae are reared in peat without transference and vermiculite with transference.

Key words: rearing methods; laboratory; feasibility adult-larva; Diabrotica speciosa. 
Comumente conhecida como "vaquinha", Diabrotica speciosa (Germar, 1824) (Coleoptera: Chrysomelidae) é uma praga polífaga, amplamente disseminada nos estados brasileiros e em alguns países da América do Sul (Viana, 2010). Na fase adulta, alimenta-se de brotações novas, de folhas, de flores e de frutos. No Brasil, tem sido registrada causando danos em soja, em amendoim, em batata, em cucurbitaceae e, principalmente, em milho e em feijão (Milanez \& Parra, 2000; Milanez et al., 2001). Além de causar danos pelo consumo direto, o inseto também atua indiretamente, como vetor de patógenos e doenças bacterianas, para inúmeras espécies de plantas (Laumann et al., 2004).

Na fase larval, D. speciosa causa maiores danos, especialmente nas culturas do milho e da batata. No milho, as larvas alimentam-se principalmente das raízes adventícias, afetando diretamente o rendimento de grãos da cultura. Enquanto que, na cultura da batata, as larvas perfuram os tubérculos, o que reduz acentuadamente a sua qualidade comercial (Gassen, 1989; Gassen 1994).

É de extrema importância a criação de $D$. speciosa em laboratório, tanto em pesquisas básicas, como em aplicadas de um programa. É exigido um grande suprimento de insetos, beneficiando no entendimento dos fatores que determinam a dinâmica populacional da praga em condições de campo e auxiliando para o aperfeiçoamento e o desenvolvimento de métodos para o seu controle (Parra, 2001; Ávila \& Parra, 2002).

Estudos em laboratório relacionados às técnicas de criação de D. speciosa em dietas natural ou artificial já foram desenvolvidos empregando-se, como dieta natural, quase sempre, plântulas de milho (Haji 1981; Pecchioni, 1988; Milanez, 1995; Silva-Werneck et al., 1995, Ávila et al.,
2000) e, como dieta artificial, a modificada por Berger (1963), contendo $4 \mathrm{~g}$ de celulose, e preparada conforme Parra (2001).

Em dieta natural, são utilizados diferentes substratos para a germinação do milho, hospedeiro no qual as larvas se desenvolvem. Pecchioni (1988) utilizou na fase larval papel de filtro como substrato e, na fase pupal, areia fina umedecida. Silva-Werneck et al. (1995) criaram larvas de $D$. speciosa em solo arenoso autoclavado. Milanez (1995) utilizou para as larvas recém-eclodidas papel germiteste umedecido em bandejas de plástico e, após o terceiro ínstar, as larvas foram transferidas para uma bandeja de pupação contendo uma mistura de solo e de areia fina (1:1).

Segundo Ávila et al. (2000), esses sistemas de criação apresentam algumas dificuldades, tais como baixa quantidade de insetos produzidos, ocorrência frequente de fungos nas fases de desenvolvimento larval e pupal, bem como excessiva mão-de-obra para a manutenção da criação. Devido a esses fatores, utilizou-se como substrato para o desenvolvimento 'seedlings' de milho, vermiculita esterilizada e umedecida, tanto na fase larval, quanto na pupal, realizando a transferência das larvas após dez dias de desenvolvimento das mesmas.

No entanto, de acordo com Ávila et al. (2000), ainda são poucas as pesquisas realizadas visando a determinar a influência do substrato na fase larval, sendo sua manutenção dificultada em laboratório, uma vez que as condições naturais em que o inseto se desenvolve nem sempre são possíveis de serem reproduzidas em condições controladas, devido ao seu hábito subterrâneo.

A fase larval é considerada a mais critica para criação de D. speciosa em laboratório, 
devido principalmente à grande mortalidade de larvas recém-eclodidas, causada por condições desfavoráveis no seu ambiente de desenvolvimento (Milanez, 1995). Assim, o objetivo deste trabalho foi aperfeiçoar o método de criação de D. speciosa em substrato turfa e vermiculita, bem como a influência do mesmo na fase adulta.

\section{Material e Métodos}

O experimento foi realizado no Núcleo de Manejo Integrado de Pragas (Numip) da Embrapa Clima Temperado, no município do Capão-doLeão, no estado do Rio Grande do Sul, em março de 2012 .

Para o aperfeiçoamento da técnica de criação de larvas $D$. speciosa, foram utilizados quatro tratamentos: vermiculita e turfa como substratos; e, como técnica de criação, a transferência após dez dias de desenvolvimento e sem transferência.

Para criação, foram utilizados recipientes de plástico $(15 \mathrm{~cm}$ de diâmetro $\mathrm{x} 7 \mathrm{~cm}$ de altura), nos quais as sementes de milho (Zea mays L.) foram colocadas para germinar em vermiculita fina esterilizada e em turfa umedecidas com água destilada.

A metodologia utilizada foi a descrita por Ávila et al. (2000), que utiliza como alimento para a fase larval plântulas de milho depositadas em vermiculita umedecida com a seguinte modificação: semeadura de 80 sementes de milho por recipiente; e, seis dias após germinação, foi realizada a inoculação de 40 larvas recém-eclodidas. No tratamento com transferência, as larvas foram transferidas para um novo recipiente com milho germinado, após dez dias de seu desenvolvimento, e, no tratamento sem transferência, as larvas permaneceram no mesmo recipiente até a emergência dos adultos.

O tratamento com turfa foi baseado na metodologia utilizada por Ávila et al. (2000), em que foram pesados $170 \mathrm{~g}$ de turfa, material de origem vegetal parcialmente decomposto, no fundo de cada recipiente e, sobre essa, $85 \mathrm{~g}$ de água. Após, foi realizado o mesmo procedimento que para vermiculita, com exceção do constante umedecimento.

Os adultos que emergiram foram separados por sexo, conforme descrito por White (1977). Os casais formados foram mantidos em pequenas gaiolas de acrílico transparentes $(13 \mathrm{~cm}$ de altura x $8 \mathrm{~cm}$ de base x $6 \mathrm{~cm}$ de topo) desprovidas de fundo, o qual foi substituído por tecido tipo 'voile', fixado com elástico de borracha. Em cada gaiola, foi acondicionado um casal de $D$. speciosa.

Como alimento para adultos, foram fornecidos folíolos de feijão (Phaseolus vulgaris L.) mantidos em frascos de vidro de $4 \mathrm{~mL}$ com água destilada, rodelas de cenoura (Daucus carota L.) e algodão hidrófilo umedecido com solução de mel a $10 \%$, todos colocados no interior da gaiola em uma placa de Petri, sobre um prato plástico forrado com papel de filtro. Como substrato de oviposição, foi fornecida gaze de coloração preta, umedecida sempre que necessário. A cada quatro dias, o alimento foi trocado e também foi realizada a contagem do número de ovos em cada gaiola, sendo que a segunda postura foi separada para a determinação da viabilidade dos ovos, conforme Ávila et al. (2000).

$\mathrm{O}$ ensaio foi conduzido em condições controladas de temperatura $\left(25 \pm 2{ }^{\circ} \mathrm{C}\right)$, umidade relativa de $60 \% \pm 10 \%$ e fototase de $14 \mathrm{~h}$. 
Avaliaram-se a duração e a viabilidade do período larval, o período de pré-oviposição (período estabelecido entre a emergência da fêmea e o início da postura), as fecundidades $\left(\mathrm{n}^{\circ}\right.$ de ovos / fêmea) total e média, o período de oviposição (período de postura dos ovos) e a longevidade de machos e de fêmeas em cada tratamento.

A partir dos dados de sobrevivência e de oviposição, foram elaboradas tabelas de vida de fertilidade (Silveira Neto et al., 1976). Posteriormente, calcularam-se o número médio de ovos por fêmea $(\mathrm{mx})$ em cada data de oviposição (x) considerando o total de fêmeas, o índice de sobrevivência acumulado de fêmeas (lx) durante o período de oviposição e o número de descendentes que atingiram a idade $x$.

Com base nas informações das tabelas de vida, estimaram-se os seguintes parâmetros para cada tratamento: intervalo entre gerações (T), que representa o tempo médio entre a postura de ovos de uma geração e a postura da geração seguinte; taxa líquida de reprodução (Ro), que é a estimativa do número médio de fêmeas gerado por fêmea ao longo do período de oviposição e que chegarão à geração seguinte; taxa intrínseca de crescimento (rm), que é o fator relacionado com a velocidade de crescimento da população; e a taxa finita de aumento $(\lambda)$, que é o fator de multiplicação de crescimento diário da população (Maia et al., 2000).

$\mathrm{O}$ ensaio foi conduzido em delineamento inteiramente casualisado, o número de repetições de cada tratamento na fase larval foi quatro e, na fase adulta, foi determinado conforme número de adultos emergidos, em que os tratamentos turfa sem transferência constituíram-se de 18 repetições, vermiculita com transferência de 20 repetições e vermiculita sem transferência de 11 repetições.

Os dados dos parâmetros avaliados foram submetidos à análise de variância, sendo as médias comparadas pelo teste de Tukey a 5\% de probabilidade, utilizando o programa Genes (Cruz, 2010).

\section{Resultados e Discussão}

Com relação à viabilidade do período larval, foi observada diferença entre os substratos e as técnicas de criação empregadas (transferência), em que se obtiveram uma viabilidade maior no tratamento sem transferência e no tratamento com transferência, quando usados como substratos turfa e vermiculita, respectivamente (Tabela

TABELA 1. Viabilidade (\%) e duração do período larval (dias) de adultos de Diabrotica speciosa submetidos a diferentes substratos e técnicas de criação (Capão-do-Leão, 2012).

\begin{tabular}{|c|c|c|c|c|}
\hline \multirow{2}{*}{ Substrato $^{1}$} & \multicolumn{2}{|c|}{ Viabilidade (\%) } & \multicolumn{2}{|c|}{ Duração (dias) } \\
\hline & Sem transferência & Com transferência & Sem transferência & Com transferência \\
\hline Turfa & $38,75 \mathrm{Aa}$ & $26,25 \mathrm{Bb}$ & $24,75 \mathrm{Bb}$ & $25,25 \mathrm{Ab}$ \\
\hline Vermiculita & $16,87 \mathrm{Bb}$ & $40,62 \mathrm{Aa}$ & $38,00 \mathrm{Aa}$ & $38,00 \mathrm{Aa}$ \\
\hline $\mathrm{CV}(\%)$ & 48,65 & 86,12 & 4,65 & 4,61 \\
\hline
\end{tabular}


1). Valores semelhantes foram observados por Bitencourt (2007), que obteve viabilidade de $25,80 \%$ de larvas criadas em substrato vermiculita. No entanto, os valores foram muito inferiores aos observados por Branson et al. (1988), que obtiveram uma viabilidade média de $72,70 \%$ para a criação de Diabrotica virgifera virgifera LeConte em dieta natural em um substrato constituído de papel de germinação e solo, e Ávila et al. (2000), ao criar larvas em dieta natural em vermiculita, que obtiveram uma viabilidade de $75,70 \%$.

No período larval, também houve influência dos tratamentos aplicados (Tabela 1). O maior período larval (38,00 dias) foi observado quando os insetos foram criados em substrato vermiculita, independente da transferência, diferente do que foi observado por Ávila et al. (2000) e por Bitencourt (2007), 23,40 e 25,80 dias com dieta natural ('seedlings' de milho) em vermiculita, respectivamente. Já Pecchioni (1988), utilizando plântulas de milho em papel durante a fase larval e areia fina umedecida para a pupação de $D$. speciosa, encontrou uma duração média do período larva-adulto de 29,20 dias. Silva-Werneck et al. (1995), fornecendo essa mesma dieta em solo arenoso autoclavado, para o desenvolvimento larval e pupal, obtiveram a duração de 26,10 dias.

No entanto, o período larval em 'seedlings' de milho no substrato turfa foi menor, 24,75 e 25,25 dias para sem e com transferência, respectivamente. Valores semelhantes foram observados por Milanez (1995), que obteve 29,20 dias para larvas criadas em raízes seminais de milho em papel germiteste e após transferidas para uma bandeja de pupação contendo uma mistura de 1:1 de solo e areia fina. Esse período mais curto pode se dever ao fato de a turfa se assemelhar mais ao solo, em relação à coloração escura, ambiente de preferência de $D$. speciosa para oviposição e para desenvolvimento da fase jovem.

No entanto, no tratamento turfa com transferência, as larvas que se desenvolveram originaram adultos deformados, que morreram logo após a emergência, não sendo possível formar casais para avaliação dos parâmetros biológicos.

Com relação aos parâmetros biológicos dos adultos de D. speciosa, verificou-se que o período de pré-oviposição desses adultos provenientes de larvas criadas em diferentes substratos e técnicas de criação não foi influenciado significativamente,

TABELA 2: Período de pré-oviposição (PPO) \pm (Erro Padrão), oviposição (PO) e fecundidade total de adultos \pm EP de Diabrotica speciosa submetidos a diferentes substratos e técnicas de criação (Capão-do-Leão, 2012).

\begin{tabular}{cccc}
\hline Tratamento $^{1,2}$ & PPO & PO & Fecundidade \\
\hline Turfa sem transferência & $18,88 \pm 2,42 \mathrm{~A} \mathrm{[15]}$ & $29,35 \pm 6,64 \mathrm{~A}[15]$ & $346,95 \pm 72,83 \mathrm{~A}[15]$ \\
Vermiculita sem transferência & $24,00 \pm 5,35 \mathrm{~A}[4]$ & $27,10 \pm 8,85 \mathrm{~A}[4]$ & $340,00 \pm 94,41 \mathrm{~A}[4]$ \\
Vermiculita com transferência & $22,70 \pm 2,73 \mathrm{~A} \mathrm{[17]}$ & $31,15 \pm 5,8 \mathrm{~A}[17]$ & $369,45 \pm 73,33 \mathrm{~A}[17]$ \\
\hline Média Geral & 21,9 & 29,2 & 5791,33 \\
\hline CV (\%) & 42,15 & 63,30 & 70,13 \\
\hline $\begin{array}{l}{ }^{1} \text { Médias seguidas de mesma letra, maiúscula na coluna, não diferem entre si, ao nível de 5\%, pelo teste de Tukey. }{ }^{2} \text { Valores entre col- } \\
\text { chetes expressam o número de observações. }\end{array}$
\end{tabular}


com uma média de $18,90,24,00$ e 22,70 dias para os insetos criados em turfa sem transferência, vermiculita sem e com transferência, respectivamente (Tabela 2). Já Milanez (1995) observou um período de pré-oviposição inferior, 10,9 dias para adultos originários de larvas criadas em papel germiteste e após transferidas para um bandeja contendo solo e areia fina (1:1). Valores semelhantes aos obtidos por Ávila et al. (2000), 10,20 e 9,90 dias para insetos criados em dieta natural em vermiculita e em papel na fase larval, respectivamente.

O período de oviposição (Tabela 2) também não foi influenciado pelos diferentes substratos e técnicas de criação, obtendo 29,35, 27,10 e 31,15 dias para turfa sem transferência, vermiculita sem e com transferência, respectivamente. Esses resultados foram inferiores aos obtidos por Milanez (1995), 40,2 dias de oviposição, e Ávila et al. (2000), 61,1 dias. Já Haji (1981), Carvalho \& Hohmann (1982) e Silva-Werneck et al. (1995) registraram valores expressivamente inferiores, que foram 8,99; 5,40 e 16,60 dias, respectivamente. Os dados dos períodos de oviposição obtidos corroboram com a informação fornecida por Lew \& Ball (1980), que afirmaram que os espermatóforos inseminados em fêmeas de $D$. virgifera desapareciam em sete dias, mas os espermatozóides permaneciam viáveis por um período de 40 dias.

Em relação ao número médio de ovos obtidos por fêmea de $D$. speciosa, também não foi constatada diferença significativa entre os diferentes tratamentos (Tabela 2). Valores semelhantes foram encontrados por Silva-Werneck et al. (1995), que obtiveram 384,60 ovos por fêmea. No entanto, foram inferiores aos encontrados por Milanez (1995) e Ávila et al. (2000), 1011 e 1724,10 ovos / fêmea, respectivamente, semelhantes aos obtidos por Pecchioni et al. (2000), que observaram 1441,75 ovos / fêmea. De acordo Ávila et al. (2000), essas diferenças de fecundidade podem ser atribuídas às técnicas distintas empregadas para a criação do inseto, bem como às diferentes metodologias utilizadas para manutenção dos adultos.

A longevidade de adultos machos e fêmeas, bem como a longevidade entre indivíduos machos e fêmeas de cada tratamento, não foram afetadas pelos diferentes substratos e técnicas de criação (Tabela 3). Ávila et al. (2000) também não observaram influência na longevidade de machos e fêmeas dos insetos adultos provenientes de larvas

TABELA 3: Longevidade de machos e fêmeas \pm (Erro Padrão) e viabilidade de ovos adultos de Diabrotica speciosa submetidos a diferentes substratos e técnicas de criação (Capão-do-Leão, 2012).

\begin{tabular}{cccc}
\hline Tratamento $^{1,2}$ & Longevidade macho & Longevidade fêmea & Viabilidade (\%) \\
\hline Turfa sem transferência & $67,55 \pm 12,68 \mathrm{Aa}[18]$ & $62,77 \pm 9,40 \mathrm{Aa}[20]$ & $84,17 \pm 2,97 \mathrm{~B}[9]$ \\
Vermiculita sem transferência & $49,28 \pm 21,33 \mathrm{Aa}[11]$ & $76,36 \pm 23,32 \mathrm{Aa}[11]$ & $94,21 \pm 0,96 \mathrm{~A}[3]$ \\
Vermiculita com transferência & $50,55 \pm 10,62 \mathrm{Aa}[20]$ & $52,10 \pm 7,97 \mathrm{Aa}[20]$ & $42,04 \pm 5,20 \mathrm{C}[6]$ \\
\hline Média Geral & 55,79 & 63,74 & 73,47 \\
\hline CV (\%) & 89.50 & 70.17 & 12,09
\end{tabular}

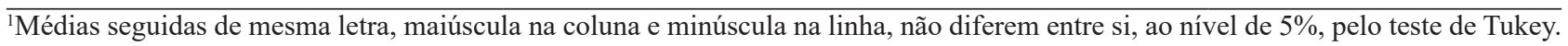
${ }^{2}$ Valores entre colchetes expressam o número de observações. 
criadas com dieta natural mantida em vermiculita e em papel. Porém, houve diferença significativa quando foram utilizados adultos provenientes de sistema de criação em dieta artificial.

Em relação à viabilidade dos ovos de $D$. speciosa, neste trabalho houve diferença significativa na porcentagem de larvas eclodidas nos diferentes tratamentos (Tabela 3). O maior valor de viabilidade foi verificado no tratamento sem transferência, 84,17 e 94,21\% para turfa e vermiculita, respectivamente. Esses resultados corroboram com Milanez (1995), que observou uma viabilidade média de $73,70 \%$. No entanto, para o tratamento com transferência, utilizando vermiculita como substrato, se obteve um percentual menor de viabilidade $(42,04 \%)$, semelhante aos resultados encontrados por Bitencourt (2007), que obteve uma viabilidade média de ovos de $21 \%$, provenientes de adultos conduzidos na fase larval em substrato vermiculita.

A duração média de uma geração $(\mathrm{T})$ foi de 10,28 semanas para turfa sem transferência, de 11,33 semanas para vermiculita sem transferência e de 9,33 para vermiculita com transferência. A taxa líquida de reprodução (Ro), a capacidade inata de aumentar em número (rm) e a razão finita de aumento $(\lambda)$, ou seja, o número de fêmeas adicionadas à população por fêmea que dará fêmea, para D. speciosa em turfa sem transferência foi de 118,$17 ; 0,69$ e 2,00, respectivamente; já para vermiculita sem transferência, foi de 34,79; 0,10 e 1,11 , e para vermiculita com transferência, foi de 131,34; 0,14 e 1,16 (Tabela 4).

Esses resultados indicam que, decorridos 71 dias (duração média da geração), podem-se esperar cerca de 120 e 131 fêmeas resultantes de cada fêmea, para turfa sem transferência e vermiculita com transferência, respectivamente, em fase de reprodução, e, quando as larvas foram criadas em vermiculita sem transferência, esse número caiu para aproximadamente 34 fêmeas resultantes por fêmea.

\section{Conclusões}

Em condições de laboratório para a fase larval, os dois substratos utilizados são adequados. A maior viabilidade larval, quando criadas em turfa sem transferência e em vermiculita com transferência, originam adultos com elevado potencial de reprodução.

\section{Agradecimentos}

Ao convênio Embrapa / Monsanto, pelos recursos.

TABELA 4: Taxa líquida de reprodução (Ro), duração média em semanas de uma geração (T), capacidade inata de aumentar em número (rm) e razão finita de aumento $(\lambda)$ de adultos de Diabrotica speciosa submetidos a diferentes substratos e técnicas de criação (Capão-do-Leão, 2012).

\begin{tabular}{ccccc}
\hline Tratamento & Ro & $\mathrm{T}$ & $\mathrm{rm}$ & $\Lambda$ \\
\hline Turfa sem transferência & 118,17 & 10,28 & 0,69 & 2,00 \\
Vermiculita sem transferência & 34,79 & 11,33 & 0,10 & 1,11 \\
Vermiculita com transferência & 131,34 & 9,33 & 0,14 & 1,16 \\
\hline
\end{tabular}


Referências

ÁVILA, C. J.; PARRA, J. R. P. Desenvolvimento de Diabrotica speciosa (Germar) (Coleoptera: Chrysomelidae) em diferentes hospedeiros. Ciência Rural, Santa Maria, v. 32, n. 5, p. 739-743, 2002.

ÁVILA, C. J.; TABAI, A. C. P.; PARRA, J. R. P. Comparação de técnicas para a criação de Diabrotica speciosa (Germar) (Coleoptero: Chrysomelidae) em dieta natural e artificial. Anais da Sociedade Entomológica do Brasil, Londrina, v. 29, n. 2, p. 257-267, 2000.

BRANSON, T. F.; JACKSON, J. J.; SUTTER, G. R. Improved method for rearing Diabrotica virgifera virgifera (Coleoptera: Crysomelidae). Journal of Economic Entomology, Lanham, v. 81, n.1, p. 410-414, 1988.

BERGER, R. S. Laboratory techniques for rearing Heliothis species on artificial medium. USDA: Agricultural Research Service, 1963. $4 \mathrm{p}$.

BITENCOURT, D. R. Biologia, capacidade reprodutiva e consumo foliar de Diabrotica speciosa (German, 1824) (Coleoptera: Chrysomelidae) em diferentes hospedeiros. 2007. 48 f. Dissertação(Mestrado) Universidade Federal da Grande Dourados, Dourados.

CARVALHO, S. M. D; HOHMANN, C. L. Biologia e consumo foliar de Diabrotica speciosa (Germar, 1824) em feijoeiro (Phaseolus vulgaris L., 1753) em condições de laboratório. In: REUNIÃO NACIONAL DE PESQUISA DE FEIJÃO, 1., 1982, Goiânia. Anais... Goiânia: EMBRAPA-CNPAF, 1982. p. 244-
245. (EMBRAPA-CNPAF. Documentos, 1).

CRUZ, C. D. Programa Genes - Aplicativo computacional em genética e estatística. Disponível em: <www.ufv/dbg/genes/genes. htm 2010>. Acesso em: 5 mar. 2013.

GASSEN, D. N. Insetos subterrâneos prejudiciais às culturas no sul do Brasil. Passo Fundo: EMBRAPA-CNPT, 1989. . ( EMBRAPACNPT. Documentos 13).

GASSEN, D. N. Pragas associadas à cultura do milho. Passo Fundo: Aldeia Norte, 1994. 92 $\mathrm{p}$

HAJI, N. F. P. Biologia, dano e controle do adulto de Diabrotica speciosa (Germar, 1824) (Coleoptera: Chrysomelidade) na cultura da batatinha (Solanum tuberosum L.). Piracicaba, 1981. 53 f. Tese (Doutorado em Entomologia) - Escola Superior de Agricultura "Luiz de Queiroz", Universidade de São Paulo, Piracicaba.

LAUMANN, R.; RIBEIRO, P. H.; PIRES, C. S. S.; SCHMID, F. G. V.; BORGES, M. M. C.; MORAES, B.; SUJII, E. R. Diversidade de crisomelídeos-praga (Coleoptera: Chrysomelidae) no Distrito Federal. Brasília, DF: Embrapa Recursos Genéticos e Biotecnologia, 2004. 22 p. (Embrapa Recursos Genéticos e Biotecnologia. Boletim de pesquisa e desenvolvimento, D6).

LEW, A. C.; BALL, H. H. Effect of copulation time on spermatozoan transfer od Diabrotica virgifera (Coleoptera: Crysomelidae). Annual Entomology Society of America, Lanham, v. 85 , n. 6, p. 2425-2432, 1980.

MAIA, H. N. M.; LUIZ, A. J. B.; CAMPANHOLA, C. Statistical inference on associated fertility life table parameters using jackknife 
technique: computational aspects. Journal of

Economic Entomology, Lanham, v. 93, n. 2, p. 511-518, 2000.

MILANEZ, J. M. Técnicas de criação e bioecologia de Diabrotica speciosa (Germar, 1824) (Coleoptera: Chrysomelidae). 1995. 102 f. Tese (Doutorado) Escola Superior de Agricultura "Luiz de Queiroz", Universidade de São Paulo, Piracicaba.

MILANEZ, J. M.; PARRA, J. R. P. Biologia e exigências térmicas de Diabrotica speciosa (Germar) (Coleoptera: Chrysomelidae) em laboratório. Anais da Sociedade Entomológica do Brasil, Londrina, v. 29, n. 1, p. 23-29, 2000.

MILANEZ, J. M.; CORTINA, J. V.; LAJUS, C. R.; MENEGUZZI, Z.; CHIARADIA, L. A. Estudos da altura de vôo e flutuação populacional de Diabrotica speciosa (Coleoptera: Chrysomelidae). In: REUNIÃO SUL BRASILEIRA DE PRAGAS DE SOLO, 8., 2001, Londrina. Anais... Londrina: Embrapa Soja, 2001. p. 253-254, (Embrapa Soja. Documentos, 172).

PARRA, J. R. P. Técnicas de criação de insetos para programas de controle biológico. Piracicaba: ESALQ, 2001. 134 p.

PECCHIONI, M. T. D. Crianza de Diabrotica speciosa (Coleoptera: Chrysomelidae) bajo condiciones de laboratorio. Revista Peruana de Entomologia, Lima, v. 31, p. 86-90, 1988. PECCHIONI, M. T. D.; CABRERA, N.; LAGUZZI, S. M.; NOVARA, C. . Aspectos Morfológicos y Poblacionales de Diabrotica speciosa speciosa (Germar) (Coleoptera: Chrysomelidae) en Condiciones de Laboratorio. Anais da Sociedade Entomológica do Brasil, Londrina, v. 29, n. 2, p. 285-294, 2000.

SILVA-WERNECK, J. O.; DE FARIA, M. R.; ABREU NETO M. V. Técnica de criação de Diabrotica speciosa (Germ.) (Coleoptera: Chrysomelidae) para bioensaios com bacilos e fungos entomopatogênicos. Anais da Sociedade Entomológica do Brasil, Piracicaba, v. 24, n. 1, p. 45-52, 1995.

SILVEIRA NETO, S.; NAKANO, O.; BARBIN, D.; VILA NOVA, N. A. Manual de ecologia de insetos. Piracicaba: Ceres, 1976. 419 p.

VIANA, P. A. Manejo de Diabrotica speciosa na cultura do milho. Sete Lagoas: Embrapa Milho e Sorgo, 2010. 6 p. (Embrapa Milho e Sorgo. Circular Técnica, 141).

WHITE, R. Sexual characters of species of Diabrotica (Chrysomelidae: Coleoptera). Annals Entomological Society American, Lanham, v. 70, p. 168, 1977. 